\title{
Impact of Quality of Healthcare Services on Consumer's Satisfaction at Primary Healthcare Centers
}

\author{
Tariq Yassen Taha ${ }^{1}$, Wissam Jabbar Qassim ${ }^{2}$ \\ ${ }^{1} \mathrm{PhD}(\mathrm{c})$, Research Scholar, University of Baghdad, College of Nursing, ${ }^{2}$ Assistant Professor (PhD), \\ University of Baghdad,College of Nursing, Community Health Nursing Department
}

\begin{abstract}
Background: Current trend in quality healthcare services is to work toward providing 'people-centered', healthcare that puts the consumers at the center in the health delivery system. This study aims to determine the level of quality of healthcare services in primary healthcare centers.

Method: The study included a simple random sample of (180) health and medical care providers in primary healthcare centers in Baghdad City by (5-8) healthcare providers for each center.

The study results showed that the general evaluation of the quality of primary healthcare services is highly efficient and that the result has a significant impact on the beneficiaries' satisfaction.

Conclusion: The researchers concluded that the primary healthcare centers are not commensurate with the increasing population density, and the lack of an ambulance in most of the primary healthcare centers. Furthermore, the level of confidence in our health institutions regarding service efficiency indicates a high level.
\end{abstract}

Keywords: Quality of Healthcare Services; Consumer's Satisfaction; Primary Healthcare Centers.

\section{Introduction}

Current trend in quality healthcare services is to work toward providing 'people-centered', healthcare that puts the consumers at the center in the health delivery system. This means that consumers' views and evaluation of services provided are critical in providing feedback for improving the quality of care provided ${ }^{(1)}$. Quality is directly connected with meeting requirements, expectations, and needs of customers. Whether a service will be reused also depends on adequate quality, especially nowadays, when production processes are of approximate and high quality. In such conditions, proper and perfect execution of logistics services can have

\section{Corresponding Author:}

\section{Tariq Yassen Taha}

$\mathrm{PhD}(\mathrm{c})$, Research Scholar, University of Baghdad,

College of Nursing

e-mail: tareq_alrubeiy@yahoo.com a crucial impact on its reuse. It is important to strive constantly for higher goals and their achievements. It requires also an adequate methodology that can help improve the quality measurement of logistics services ${ }^{(2)}$.

Service quality is generally finding of services given to consumers. It depends on the customer judgment. The comparison of expectations next and previous used services is the result of service quality and identifies procedure of the service transfer is known service quality perception $^{(1)}$.

It is also service quality dimension until SERVQUAL (service quality) model;measures do not contemplate it as. Extensive perspective, human perspectives and its origination also service quality measures as these restrictions $^{(3)}$.

\section{Method}

A descriptive study was conducted at Primary Healthcare in Baghdad City from January $13^{\text {th }}$, to March 
$5^{\text {th }}, 2019$. The study included a simple random sample of (180) healthcare providers in primary healthcare centers in Baghdad City (5-8) healthcare providers for each center using a questionnaire for the quality of services and using the method of distributing questionnaires to the various specialties working in the health center, these centers are distributed into (2) sides and divided into (8) health sectors according to ministry of health directorate of primary healthcare. A total of (28) primary healthcare centers are selected for the purpose of the study.
The data collection starts with providers primary healthcare services in primary healthcare centers in Baghdad City using a questionnaire and the interview technique as means of data collection.

The reliability of the questionnaire was determined through a pilot study and the validity are achieved through a panel of (17) experts. A pilot study included a convenient sample of (17) provider were selected among persons concerned with primary healthcare centers.

\section{Results and Discussion}

Table 1. Overallevaluation of healthcare system and structure $(\mathrm{N}=28)$

\begin{tabular}{|c|c|c|c|c|}
\hline Evaluation & f & $\%$ & M.S & SD \\
\hline Inefficient & 0 & 0 & \multirow{4}{*}{2.79} & \multirow{4}{*}{0.418} \\
\hline Efficient & 6 & 21.4 & & \\
\hline Highly efficient & 22 & 78.6 & & \\
\hline Total & 28 & 100 & & \\
\hline
\end{tabular}

f: Frequency, \%: Percentage, M.S: Mean of score, SD: Standard Deviation Inefficient $=0-8$, Efficient $=9-17$, Highly efficient $=18-26$

More of centers are highly efficient (78.6\%) and (21.4\%) are showing efficient system and structure.

Table 2. Caregivers personal characteristics $(N=180)$

\begin{tabular}{|c|c|c|c|c|c|c|}
\hline No. & & f & $\%$ & $x^{2}$ & df & p-value (Sig) \\
\hline \multirow{7}{*}{1} & \multicolumn{6}{|l|}{ Age } \\
\hline & $20-29$ years & 16 & 8.9 & \multirow{6}{*}{5.213} & \multirow{6}{*}{8} & \multirow{6}{*}{$\begin{array}{c}.735 \\
\text { (N.S) }\end{array}$} \\
\hline & $30-39$ years & 43 & 23.9 & & & \\
\hline & $40-49$ years & 49 & 27.2 & & & \\
\hline & $50-59$ years & 63 & 35 & & & \\
\hline & $60 \leq$ years & 9 & 5 & & & \\
\hline & Total & 180 & 100 & & & \\
\hline \multirow{4}{*}{2} & \multicolumn{6}{|l|}{ Gender } \\
\hline & Male & 83 & 46.1 & \multirow{3}{*}{2.159} & \multirow{3}{*}{2} & \multirow{3}{*}{$\begin{array}{c}.340 \\
\text { (N.S) }\end{array}$} \\
\hline & Female & 97 & 53.9 & & & \\
\hline & Total & 180 & 100 & & & \\
\hline \multirow{7}{*}{3} & Level of education & & & & & \\
\hline & Secondary school & 15 & 8.3 & \multirow{6}{*}{4.132} & \multirow{6}{*}{8} & \multirow{6}{*}{$\begin{array}{c}.845 \\
\text { (N.S) }\end{array}$} \\
\hline & Diploma & 61 & 33.9 & & & \\
\hline & Bachelor & 87 & 48.3 & & & \\
\hline & Master & 6 & 3.3 & & & \\
\hline & Doctorate & 11 & 6.1 & & & \\
\hline & Total & 180 & 100 & & & \\
\hline
\end{tabular}




\begin{tabular}{|c|c|c|c|c|c|c|}
\hline No. & & f & $\%$ & $\chi^{2}$ & df & p-value (Sig) \\
\hline \multirow{10}{*}{4} & \multicolumn{6}{|l|}{ Speciality } \\
\hline & Physician & 71 & 39.4 & \multirow{9}{*}{20.151} & \multirow{9}{*}{14} & \multirow{9}{*}{$\begin{array}{l}.125 \\
\text { (N.S) }\end{array}$} \\
\hline & Nurse & 41 & 22.9 & & & \\
\hline & Radial photographer & 15 & 8.3 & & & \\
\hline & Biologist & 15 & 8.3 & & & \\
\hline & Chemist & 3 & 1.7 & & & \\
\hline & Pharmacist & 11 & 6.1 & & & \\
\hline & Medical technician & 22 & 12.2 & & & \\
\hline & Vital statistician & 2 & 1.1 & & & \\
\hline & Total & 180 & 100 & & & \\
\hline \multirow{7}{*}{5} & Years of service & & & & & \\
\hline & $\leq 5$ years & 13 & 7.2 & \multirow{6}{*}{2.960} & \multirow{6}{*}{8} & \multirow{6}{*}{$\begin{array}{c}.937 \\
\text { (N.S) }\end{array}$} \\
\hline & $6-10$ years & 26 & 14.4 & & & \\
\hline & $11-15$ years & 30 & 16.7 & & & \\
\hline & $16-20$ years & 29 & 16.1 & & & \\
\hline & $21 \leq$ years & 82 & 45.6 & & & \\
\hline & Total & 180 & 100 & & & \\
\hline
\end{tabular}

No: Number, f: Frequency, \%: Percentage, ${ }_{\chi}^{2}=$ Chi-square, df: degree of freedom, p-Value: probability value, Sig: Significance, N.S: Not significant

More than a third of healthcaregivers age 50-59-years (35\%), morethan a half are females $(53.9 \%)$, less than a half hold a bachelor's degree (48.3\%) and diploma (33.9\%). It has known of specialty variable that (39.4\%) were physicians, $(22.9 \%)$ nurses, and the remaining percentage was distributed on other specialties such as: radial photographer, biologist, chemist, pharmacist, medical technician, and vital statistician. Those healthcaregivers are reported that they are working for more than 21 -years at the primary healthcare $(45.6 \%)$ as years of experience.

Table 3. Evaluation the tangibility of primary healthcare services at primary healthcare centers $(\mathrm{N}=180)$

\begin{tabular}{|c|c|c|c|}
\hline List & Tangibility items & M.S & Evaluation \\
\hline 1 & The health center needs to appliances, medical equipment and supplies used currently occur. & 2.53 & High \\
\hline 2 & $\begin{array}{l}\text { You believe that the nature of galleries and places waiting of the consumers', the doctors' offices } \\
\text { and the current employees fit with what you expect in your mind. }\end{array}$ & 1.92 & Moderate \\
\hline 3 & $\begin{array}{l}\text { There is interest by the health center management and employees in a manner and body work clothes } \\
\text { commensurate with the level of service provided. }\end{array}$ & 2.60 & High \\
\hline 4 & $\begin{array}{l}\text { You believe that the management of the health center provided the material requirements within the } \\
\text { available capabilities and commensurate with your mental expectations for it. }\end{array}$ & 2.51 & High \\
\hline \multicolumn{2}{|r|}{ Total } & 2.39 & High \\
\hline
\end{tabular}

M.S: Mean of score, Low $=1-1.66$, Moderate $=1.67-2.33$, High $=2.34-3$

Primary healthcare centers having high tangibility (M.S= 2.39) as seen in scores of mean that associated with all items except the item (2) that refer to moderate.
That mean most of healthcare centers are having enough equipment and supplies in addition to the appropriate staff that fit to mission of these centers. 
Table 4. Evaluation the reliability of primary healthcare services at primary healthcare centers $(\mathrm{N}=180)$

\begin{tabular}{|c|c|c|c|}
\hline List & Reliability items & M.S & Evaluation \\
\hline 1 & $\begin{array}{l}\text { The Health Center's management is } 9 \text { committed to ensuring that patients and consumers' } \\
\text { provide health and therapeutic services and provide the appropriate environment as you would } \\
\text { expect in your mind. }\end{array}$ & 2.65 & High \\
\hline 2 & $\begin{array}{l}\text { The health center management sympathizes with patients and consumers' when submitting } \\
\text { complaints as you expect them }\end{array}$ & 2.82 & High \\
\hline 3 & The health center management is seen to provide services on time, in a fast and accurate manner. & 2.77 & High \\
\hline 4 & $\begin{array}{l}\text { Patients and consumer's place their trust in the medical and health professional skills with } \\
\text { confidence and safety. }\end{array}$ & 2.66 & High \\
\hline 5 & $\begin{array}{l}\text { The health center's management is seen to record information about patients and consumer's and } \\
\text { their health status in records and computers. }\end{array}$ & 2.76 & High \\
\hline \multicolumn{2}{|r|}{ Total } & 2.73 & High \\
\hline
\end{tabular}

M.S: Mean of score, Low $=1-1.66$, Moderate $=1.67-2.33$, High $=2.34-3$

Primary healthcare centers are high reliable (M.S= 2.73), the mean of scores is showing high in all items that indicate a good quality of services related to reliability that represented by: primary healthcare centers are providing a therapeutic and appropriate environment for their consumers, responding to any complaints that committed to centers, providing a services in accurate time and manner, keep that trust between the consumers and staff, and working with documentation of information regarding the consumers.

Table 5. Evaluation the responsiveness of primary healthcare services at primary healthcare centers ( $\mathbf{N}=\mathbf{1 8 0})$

\begin{tabular}{|c|l|c|c|}
\hline List & Responsiveness items & M.S & Evaluation \\
\hline 1 & $\begin{array}{l}\text { It is telling patients and consumer's for times the provision of health, medical and therapeutic } \\
\text { service to them according to your perception. }\end{array}$ & 2.74 & High \\
\hline 2 & $\begin{array}{l}\text { It is not expected to get patient's and consumer's on the online service by the staff at the health } \\
\text { center. }\end{array}$ & 1.98 & Moderate \\
\hline 3 & The health center staff wants to help patients and visitors permanently. & 2.82 & High \\
\hline 4 & $\begin{array}{l}\text { Despite the busy staff to provide services, but they respond with patients and consumer's requests } \\
\text { immediately. }\end{array}$ & 2.82 & High \\
\hline & \multicolumn{1}{|c|}{ Total } & $\mathbf{2 . 5 9}$ & High \\
\hline
\end{tabular}

M.S: Mean of score, Low $=1-1.66$, Moderate $=1.67-2.33$, High $=2.34-3$

Primary healthcare centers are showing high responsiveness $(\mathrm{M} . \mathrm{S}=2.59)$ as seen in scores of mean that associated with all items except the item (2) that refer to moderate. That mean most of healthcare centers are working on telling the consumers the time of service availability, providing the expected services that meet for consumers' perception, and responding to consumers' requests immediately. 
Table 6. Evaluation the assurance of primary healthcare services at primary healthcare centers $(\mathrm{N}=180)$

\begin{tabular}{|c|l|c|c|}
\hline List & Assurance items & M.S & Evaluation \\
\hline 1 & In your opinion, patients and consumer's should have full confidence in the health center staff. & 2.85 & High \\
\hline 2 & $\begin{array}{l}\text { In your opinion, you should reassure the patient and the consumer's that he is in good hands with } \\
\text { the staff at the health center when dealing. }\end{array}$ & 2.94 & High \\
\hline 3 & $\begin{array}{l}\text { Do you feel that the medical and health staff and staff interact with patients and consumer's and } \\
\text { treat them gently and tactfully. }\end{array}$ & 2.74 & High \\
\hline 4 & $\begin{array}{l}\text { The staff of the health center have the competence, the Courteous and the credibility to perform } \\
\text { their work, which necessitates the management of the health center to provide support to these } \\
\text { workers. }\end{array}$ & 2.74 & High \\
\hline \multicolumn{2}{|c|}{ Total } & $\mathbf{2 . 8 2}$ & High \\
\hline
\end{tabular}

M.S: Mean of score, Low $=1-1.66$, Moderate $=1.67-2.33$, High $=2.34-3$

Primary healthcare centers are providing high assurance (M.S=2.82), the mean of scores is showing high in all items that indicate a good quality of services related to assurance that represented by the opinion of healthcare providers about the mission and vision of the primary healthcare that working in, it has known of findings that high confidence and opinion are expressed about the work of primary healthcare services.

\section{Discussion}

The evaluation of the structure of elements and systems in primary healthcare centers, with an average of more than $75 \%$ of the total item as good average scores in more elements. It reflects the availability of standard criteria for the system and the structure represented and device availability, complaints boxes, and wheelchair availability.

These results are consistent with the findings of ${ }^{(4)}$ who indicated that all of the above are available in $85 \%$ of primary Healthcare centers.

The Environmental Protection Agency(EPA) requirement for medical waste disposal are for waste to be segregated into categories of, sharps, toxic, hazardous, regulated or infectious fluids of greater than $20 \mathrm{ml}$. and other materials. Although incineration has long been recognized as an efficient method for disposing safely of sharps and other contaminated medical waste ${ }^{(5)}$.

While, the coverage area of the population through the services of the healthcare center, two primary healthcare centers provide healthcare services to less than $(20,000)$ consumers. While, 26 primary healthcare centers of these coverage are equal to or more than $(20,000)$. These results show that all primary healthcare centers have violated international standards (2-3 per 10,000) (Ministry of Health) regarding their coverage. This may be due to the difference in population size between the health sectors in Baghdad. Community health can be affected by the size of the population, so knowing the size of the community provides community health workers with important planning information ${ }^{(5)}$.

Concerning the presence of an ambulance in the primary healthcare centers, the results indicate that more than $(89 \%)$ of the primary healthcare centers do not have an ambulance, and these results are consistent with thatof ${ }^{(6)}$ who stated that the availability of an ambulance in primary healthcare centers at (17\%), and these results do not comply with international standards in the quality of primary healthcare services.

Regarding the evaluation of tangibility in the field of quality of healthcare services, the results indicate that primary healthcare centers with high tangibility as seen in mean of scores that associated with all items except the item (2) that refer to moderate. That mean most of healthcare centers are having enough equipment and supplies in addition to the appropriate staff that fit to mission of these centers.

The results are consistent with a study conducted by (7) (2012) in Iran who concluded that the tangibility dimension in the quality of primary healthcare centers services was high, and that is consistent with the good reputation and excellence that the care system craves Primary health in Iran, where reached.

The tangibility dimension indicates the appearance of the facilities, physical and human equipment at the health service delivery site with respect to (22) regarding the tangibility of the services in terms of availability of 
equipment and materials Means of education and the outward appearance of workers ${ }^{(8)}$.

Regarding the reliability evaluation in the quality of healthcare services, the results revealed that primary healthcare centers are highly reliability, the average score appears in all elements indicating good quality of the services related to the reliability it represents: primary healthcare centers are providing a therapeutic and appropriate environment for their consumers, responding to any complaints that committed to centers, providing a services in accurate time and manner, keep that trust between the consumers and staff, and working with documentation of information regarding the consumers. This corresponds to the good reputation of our health institutions for their services to make the level of high trust and applies to international standards to service quality.

This result is consistent with that of ${ }^{(9)}$ who indicated the positive effect of the application of reliability dimension in the evaluation of primary healthcare providers in healthcare centers.

Whereas, reliability means the ability to provide services on time and with the required accuracy, the extent of fulfillment of obligations, and the performance of health services promised by beneficiaries. It also includes adherence to the deadlines set for beneficiaries (patients) as well as seeking to preserve their files and documents from damage and loss ${ }^{(10)}$.

For the responsiveness and the quality of healthcare services, the results indicate that the primary healthcare centers show a high response as they appear in the average scores associated with all elements except for item (2) that indicates moderate. This means that most healthcare centers inform consumers when the service is available, and provide expected services that meet consumers' perceptions, and respond to consumer demands immediately, and this is felt in the tangibility analysis table, With this result, can say that the primary healthcare centers implement international standards of quality of services at a high level with regard to the responsiveness dimension. These results are consistent with the study of ${ }^{(11)}$ whostated that the response was high.

Concerning the responsiveness that is the ability and desire of the health center provider services to the beneficiaries at the time and meet ${ }^{(12)}$ to provide them appropriate to the current, future and urgent needs of patients through flexibility in procedures and means of providing services ${ }^{(13)}$. and willingness and permanent desire to provide services to patients when they need them ${ }^{(14)}$.

Regarding the assurance evaluation and the quality of healthcare services; the results showed that primary healthcare centers offer a high assurance, the average score appears in all elements indicating good quality of services related to assertion represented in the opinion of healthcare providers in Mission and vision for primary healthcare that you work in.

These results are consistent with a study conducted in United Kingdom by (20). The levels of awareness of both patients and staff on the levels of application of the dimensions of the quality of services provided in outpatient clinics and healthcare centers. The study concluded that the evaluation of workers and patients' quality dimension application levels were high for the assurance dimension.

Regarding the meaning of assurance, it means the quality of information and the policy of those responsible for providing services and their policy, and their ability to inspire confidence and respond to patient and customer inquiries. It also indicates the confidence of patients in the health center staff, and the ability of those responsible for managing the health center to provide safety and security at the place of service ${ }^{(15)}$.

Primary healthcare centers showed a high degree of empathy and mean the average scores in all items that indicate a good quality of services related to empathy, which is: giving health services with appropriate attention to consumers, and providing health according to the needs of consumers, The evaluation of empathy to this high degree It does not come out of the void, but thanks to the concerted efforts of primary healthcare providers, it gave an important impression to auditors and reached international standards for quality of services.

The results of this dimension are consistent with thatof (16)in Sao Paulo, and the features that have reached the highest levels of satisfaction are compatible with the education and commitment of the medical and nursing staff, interpretations and instructions on the user's health problem, respect for privacy and guidance for continuing care after discharge from the hospital. Empathy were the dimension that affected satisfaction, as they demonstrated a high degree of empathy. 
Referring to the sympathy dimension as it includes many variables that include the interest and care of workers who benefit from the services personally, and understanding and realizing their needs and the appropriateness of working hours and providing services in a way that suits the desires patients ${ }^{(17)}$.

Conflict of Interest: The researchers confirm that there is no any conflict of interest.

Source of Funding: This study is self-funded.

Ethical Clearance: The researchers obtained the ethical approval from the University of Baghdad, College of Nursing.

\section{Conclusion}

1. Primary healthcare centers whose numbers are not commensurate with the increasing population density, as the number of people included in the geographical area exceeds 20,000 for the main health center, and this violates the international standards for the quality of services, which stipulates that no more than 10,000 people.

2. The level of confidence in our health institutions regarding service efficiency indicates a high level, and this is high consistent with international standards for service quality.

3. An indication the evaluation of the healthcare system and structure in the primary healthcare centers, that the Criteria of the existence of a lecture hall at the health center, the evaluation (fair).

\section{Recommendations:}

\section{There is a need to:}

1. Increase the number of primary healthcare centers to fit the increasing population so that it does not exceed 10,000 people until it conforms to international standards for the quality of services.

2. Provide all primary healthcare centers with an ambulance to transport patients and critical cases to the nearest hospital.

3. Maintain the high level of confidence in our health institutions by developing the health sector with all new scientific and material capabilities to enhance the level of workers in primary healthcare centers to ensure the continued quality of healthcare services.

\section{References}

1. Walsh M, Walsh A. Measuring patient satisfaction

with nursing care: experience of using the Newcastle Satisfaction with Nursing Scale. Journal of Advanced Nursing (Wiley-Blackwell) [Internet]. 1999 Feb [cited 2020 Aug 31];29(2):307-15. Available from: https://search-ebscohost-com. ezproxy.okcu.edu/login.aspx?direct=true \& $\mathrm{db}=\mathrm{ccm} \& \mathrm{AN}=5866779 \&$ site $=$ ehost-live

2. Nowotarski P,Pasławski J,Kadler A. Quality management systems as a key element for company strategy selection-Case study. MATEC Web Conf. 2018, 222, 01012.

3. Kaura, Vinita Pasławski J,and Kadler A. Service quality, service convenience, price and fairness, customer loyalty, and the mediating role of customer satisfaction. International Journal of Bank Marketing 33 (2015): 404-422.

4. Al-Miahi, N. Determination of quality assurance for maternal and child- health services in Baghdad City. Master Thesis, University of Baghdad,College of Nursing,2010, 90.

5. Alwan Q. Total quality management and ISO 2000,9001 requirements, Amman, Dar Al Thaqafa Publishing, 2005.

6. Allender A. \& Spradley W.Community health nursing promoting and protecting the public's health, 6th ed. Philadelphia: Lippincott Williams and Wilkins, 2005,596, 599, 602, 608, 611, 614617.

7. Al-Khudairi J.Evaluation of primary healthcare system as a prerequisite for Iraqi health system reform. PHD Dissertation,Al-Mustaniriya University, College of Medicine, Community Medicine,2005,123,141.

8. Zarei A, Arab M, Froushani AR, Rashidian A, Ghazi Tabatabaei SM. Service quality of private hospitals: the Iranian patients' perspective. BMC Health Services Research [Internet]. 2012 Jan [cited 2020 Aug 29];12(1):31. Available from: https:// search-ebscohost-com.ezproxy.okcu.edu/login. aspx?direct=true \& $\mathrm{db}=\mathrm{ccm} \& \mathrm{AN}=104492433 \&$ site $=$ ehost-live

9. Kossman M. Delivering excellent service quality in aviation: A practical guide for internal and external service providers. England: Ashgate Publishing Limited, 2006.

10. Yaacob M, Zakaria Z, Salamat A, Yaacob, Z,Salmi,N, Hasan N, Razak R, and Rahim S. Patients satisfaction towards service quality in public 
hospital: Malaysia perspective. Interdisciplinary Journal of Contemporary Research in Business, 2(12): 2011, 635-640.

11. Kuhn, K.; Warren, J. and Leong, T. Building sustainable health systems, 2nd ed. United Kingdom: Gazella Books Services, 2007.

12. Anbori A. Client>s satisfaction of healthcare services in Iraq: The study and analysis of the views of client $>\mathrm{s}$ in Baghdad City, quality management and client $>s$ satisfaction,Iraqi Institute for Economic Reform Journal, 2(10),2011, 13-17.

13. Creveling C, Slutsky J. and Antis D. Design for six sigma in technology and product development.New Jersey: Prentice Hall, 2003.

14. Verma H. Services Marketing: Text and Cases, 2/e. New Delhi: Person Education in South Asia, 2012.
15. Murray C. \& Evans D. Health Systems performance assessment: Debates, method and empiricism. Geneva: World Health Organization, 2003.

16. Alwan, Q. Total quality management and ISO 2000,9001 requirements. Amman, Dar Al Thaqafa Publishing, 2005.

17. Cruz WBS, \& Melleiro MM. Assessment levels of the user's satisfaction in a private hospital. Rev Esc Enferm USP, 44(1):2010, 147-53.

18. Parasuraman A, Zeithaml VA. and Berry LL. SERVQUAL: A multi-item scale for measuring consumer perceptions of the service quality, Journal of Retailing, 64(1), 1988, 12- 40. 